\title{
Improve the Formation of Geopolymer Concrete Mixed with Seawater and Without Curing
}

\author{
Abd Allah R. Abd EL-moatey ${ }^{1}$, Ahmed S. Faried ${ }^{2}$, Waleed H. Soufi ${ }^{3}$, Magdy A. Abd El-Aziz ${ }^{2}$ \\ ${ }^{1}$ Faculty of Engineering, Fayoum University, Fayoum, Egypt \\ ${ }^{2}$ Department of Civil Engineering, Faculty of Engineering, Fayoum University, Fayoum, Egypt \\ ${ }^{3}$ Housing and Building National Research Center (HBRC), Cairo, Egypt
}

Email address:

asg00@fayoum.edu.eg (A. S. Faried)

\section{To cite this article:}

Abd Allah R. Abd EL-moatey, Ahmed S. Faried, Waleed H. Soufi, Magdy A. Abd El-Aziz. Improve the Formation of Geopolymer Concrete Mixed with Seawater and Without Curing. American Journal of Civil Engineering. Vol. 5, No. 6, 2017, pp. 344-351. doi: $10.11648 /$ j.ajce. 20170506.15

Received: June 27, 2017; Accepted: July 6, 2017; Published: October 30, 2017

\begin{abstract}
Geopolymer is a new trend in cement industry, traditional cement has prompted several problems related to health and environment due to cement dust and carbon dioxide. Geoplymer, however, has attenuated such problems due to the method of manufacturing and low emission of carbondioxide. This paper examines the ability to form geopolymer cement and the ability to use this cement in the formation of geopolymer concrete in the field. Various papers have been published with concern to the geopolymer cement set the curing in an oven is constraint to the geopolymer cement formation. During this paper are studied in air without any types of curing. Also the improvement of cement by meta koline as a source of aluminium and silica are studied. geopolymer cement based on the slag has been improved as it has been replaced with $10 \%$ metakoline. After optimizing the best mix of cement (slag and metakoline). The effect of geopolymer cement content is studied. Results have shown variation in compressive strength related directly to content of geoplymer strength. Water in geopolymer cement is not included in the reaction. So, throughout the paper the sea water is used as an alternative to fresh water. Results have shown an improvement in the compressive strength as compared to the presence of fresh water.
\end{abstract}

Keywords: Geopolymer Cement, Concrete, Ground-Granulated Blast-Furnace Slag, Metakoline, Compressive Strength

\section{Introduction}

Concrete is widely used all over the world because of its versatile application. The Portland cement (PC) is not considered a friendly environmental material. The production of PC emits large amounts of $\mathrm{CO}_{2}$ and other greenhouse gases [1]. It has been reported that the worldwide cement industry contributes around 1.65 billion tons of the greenhouse gas emissions annually [2]. Due to the production of PC, it is estimated that by the year 2020, emissions will rise by about $50 \%$ beyond current levels [3]. Research in Cement developed in the direction of low emission and geopolymer cement is present. Geopolymer cement is alkaliactivated binder produced by a polymerization reaction [4] (Davidovits, 1999). Geopolymer helps to generate less $\mathrm{CO}_{2}$ also reuses industrial waste to produce added-value construction material [5] (Malhotra, 2002). Parthiban has noted no impact of Chemical Admixture on Compressive Strength but has shown considerable increase in the workability of the concrete. 7 days strength has been found to be $70 \%$ of its 28 days strength; the 28 days strength is higher as compared to OPC [6]. The ratio of replacement of Fly ash with GGBS (up to $40 \%$ ), $8 \mathrm{M} \mathrm{NaOH}$ solution and $\mathrm{Na}_{2} \mathrm{Sio}_{3}$ $/ \mathrm{NaOH}$ has been 2.5. Results indicate that a high amount of slag is present; the compressive strength of 31.85 at 3 days [7]. The variation in GGBFS and fly ash based geopolymer at ambient temperature has shown backbone accretion slowed down after the age of 28 canicule and continues to access at a slower amount until 180 days [8]. Fly ash Geopolymer with replacement GGBFS $30 \%$ of total Binder and treatment is, at ambient Temperature, $55 \mathrm{Mpa}$ compressive strength. The compactness of the Gel increases when Slag Content is higher in the paste [9]. Geopolymers based on alkaline activation have got the highest compressive strength that has been obtained in systems activated with sodium silicate, 
which enabled geopolymer synthesis at room temperature. The results obtained in the present study demonstrate the feasibility of using concrete demolition wastes as precursors to obtain geopolymer cements [10].

\section{Experimental Procedures}

\subsection{Materials}

The materials used in this investigation are ground granulated water cooled blast Furnace slag (GGBFS) from Iron and Steel Factory- Helwan, Egypt. Meta kaoline (kaoline fired at 750 two houres) from el esyela, Egypt. It is composed of both GGBFS and MK and represented in Figures (1, and 2). While ground granulated blast furnace slag materials have been composed of amorphous constituents, the alkaline activator used has been formulated from the combination of sodium silicate and sodium hydroxide solution. The author has prepared the activator from the sodium silicate solution $\left(\mathrm{Na}_{2} \mathrm{O}=12 \%, \mathrm{SiO}_{2}=30 \%\right.$, and water $=57 \%$ by mass $)$ and sodium hydroxide $(\mathrm{NaOH})$ in flake form with $99 \%$ purity. Table (1) shows the chemical composition of MK and SLAG.

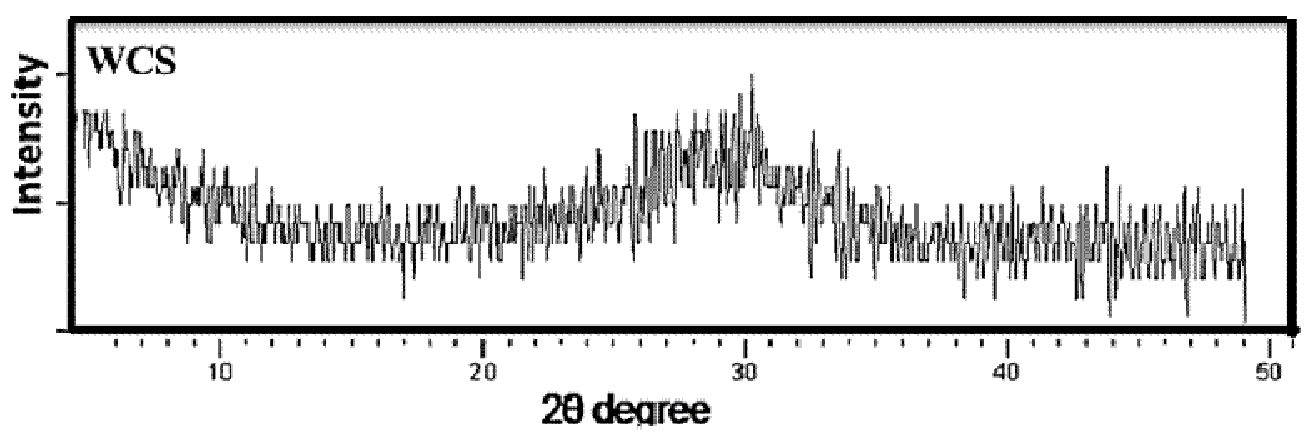

Figure 1. Mineralogical composition of water cooling slag, XRD.

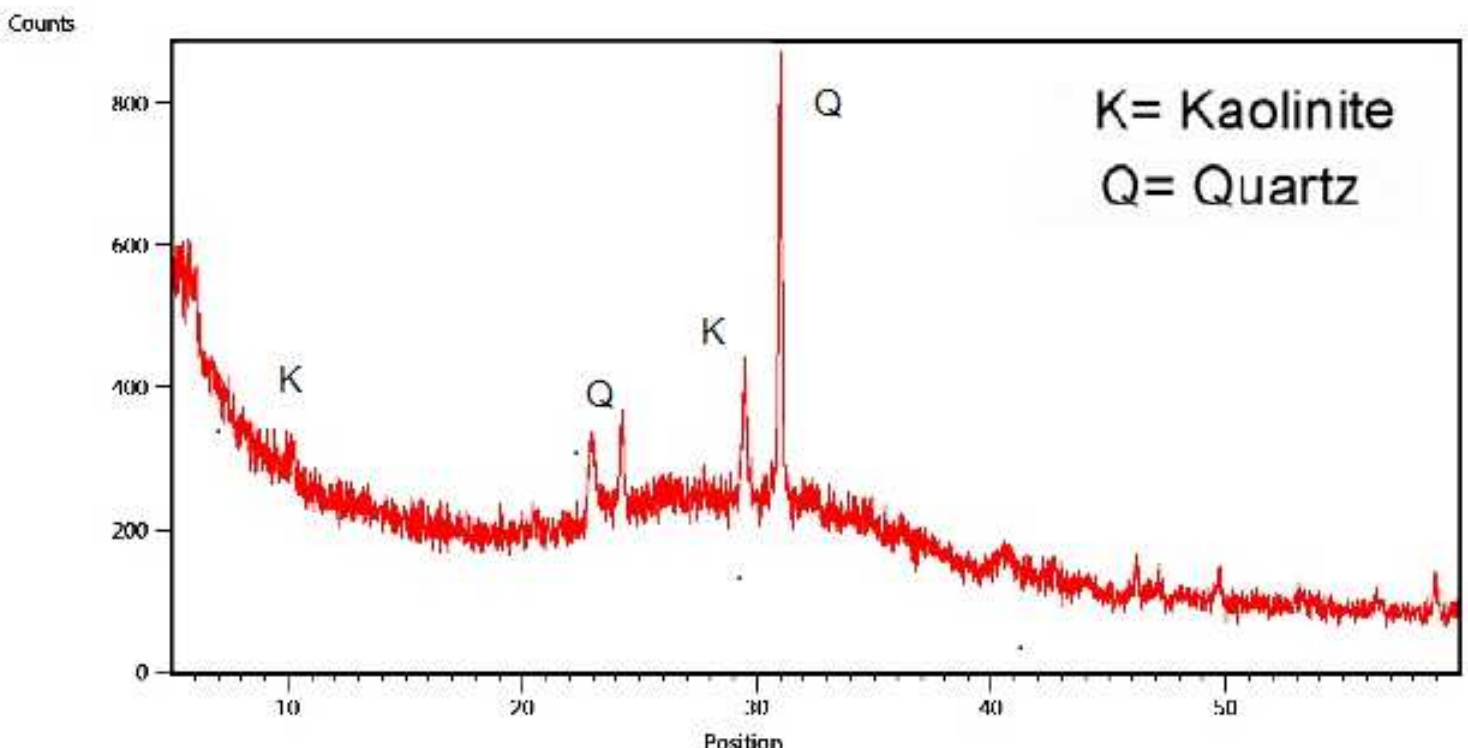

Figure 2. Mineralogical composition of meta kaoline (MK), XRD.

Table 1. XRF analysis of slag, meta-kaolin.

\begin{tabular}{|c|c|c|c|c|c|c|c|c|c|c|c|c|c|c|}
\hline $\begin{array}{l}\text { Chemical } \\
\text { compounds }\end{array}$ & $\mathrm{CaO}$ & $\mathrm{SiO}_{2}$ & $\mathbf{A l}_{2} \mathbf{O}_{3}$ & MgO & $\mathrm{Na}_{2} \mathrm{O}$ & $\mathrm{SO}_{3}$ & $\mathbf{P}_{2} \mathbf{O}_{5}$ & $\mathrm{~K}_{2} \mathrm{O}$ & $\mathrm{TiO}_{2}$ & $\mathrm{MnO}_{2}$ & $\mathrm{Fe}_{2} \mathrm{O}_{3}$ & $\mathrm{SO}_{4}$ & Cl & LOI \\
\hline GGBS & 33.07 & 36.59 & 10.01 & 6.43 & 1.39 & 3.52 & 0.10 & 0.74 & 0.52 & 3.44 & 1.48 & 0.08 & 0.05 & 2.58 \\
\hline MK & 0.14 & 55.01 & 40.94 & 0.34 & 0.09 & 0.00 & 0.00 & 0.60 & 0.55 & 0.00 & 0.55 & 0.00 & 0.00 & 1.54 \\
\hline
\end{tabular}

Local aggregates comprise $20 \mathrm{~mm}, 14 \mathrm{~mm}$ and $10 \mathrm{~mm}$ size. Coarse aggregates C. A of crushed granite-type aggregates have specific gravity of 2.74 and fineness modulus of 2.93 . Fine aggregates F. A (sand) in saturated surface dry condition have specific gravity of 2.62 fineness modulus 3.39. The C. $\mathrm{A}$ and F. A used in mixing were obtained from Minya quarries. Table (2 and 3) show sieve analysis and physical properties of C. A and F. A.

Table 2. The sieve analysis of coarse and fine aggregates.

\begin{tabular}{llllllllll}
\hline Size & $\mathbf{1 9}$ & $\mathbf{1 6}$ & $\mathbf{9 . 5}$ & $\mathbf{4 . 7 6}$ & $\mathbf{2 . 8}$ & $\mathbf{1 . 4}$ & $\mathbf{0 . 7 1}$ & $\mathbf{0 . 3 5 5}$ & $\mathbf{0 . 1 8}$ \\
\hline \%F. A & 100 & 100 & 100 & 100 & 98 & 85 & 75 & 49 & 23 \\
\%C. A & 97 & 84 & 78 & 22 & 0 & 0 & 0 & 0 & 0 \\
\hline
\end{tabular}


Table 3. The physical properties of coarse and fine aggregates.

\begin{tabular}{lll}
\hline & M. E & S. G \\
\hline F. A & 3.39 & 2.62 \\
C. A & 2.93 & 2.74 \\
\hline
\end{tabular}

\subsection{Methods of Investigation}

\subsubsection{Compressive Strength}

The test specimens were cast in steel cubic molds $(50 \times 50$ $\times 50 \mathrm{~mm})$ for binder specimens or $(100 \times 100 \times 100 \mathrm{~mm})$ for concrete specimens and compacted on a vibrating table. After approximately $24 \mathrm{~h}$, the specimens were removed from the molds. All specimens were put in the air without any types of curing.

For each mix, cubic samples were tested to determine the compressive strengths at 7 and 28 days of mixing. The compressive strength for each mixture was obtained from an average of three cubic specimens. Figure (3) shows the geopolymer concrete cubes during cast and test.

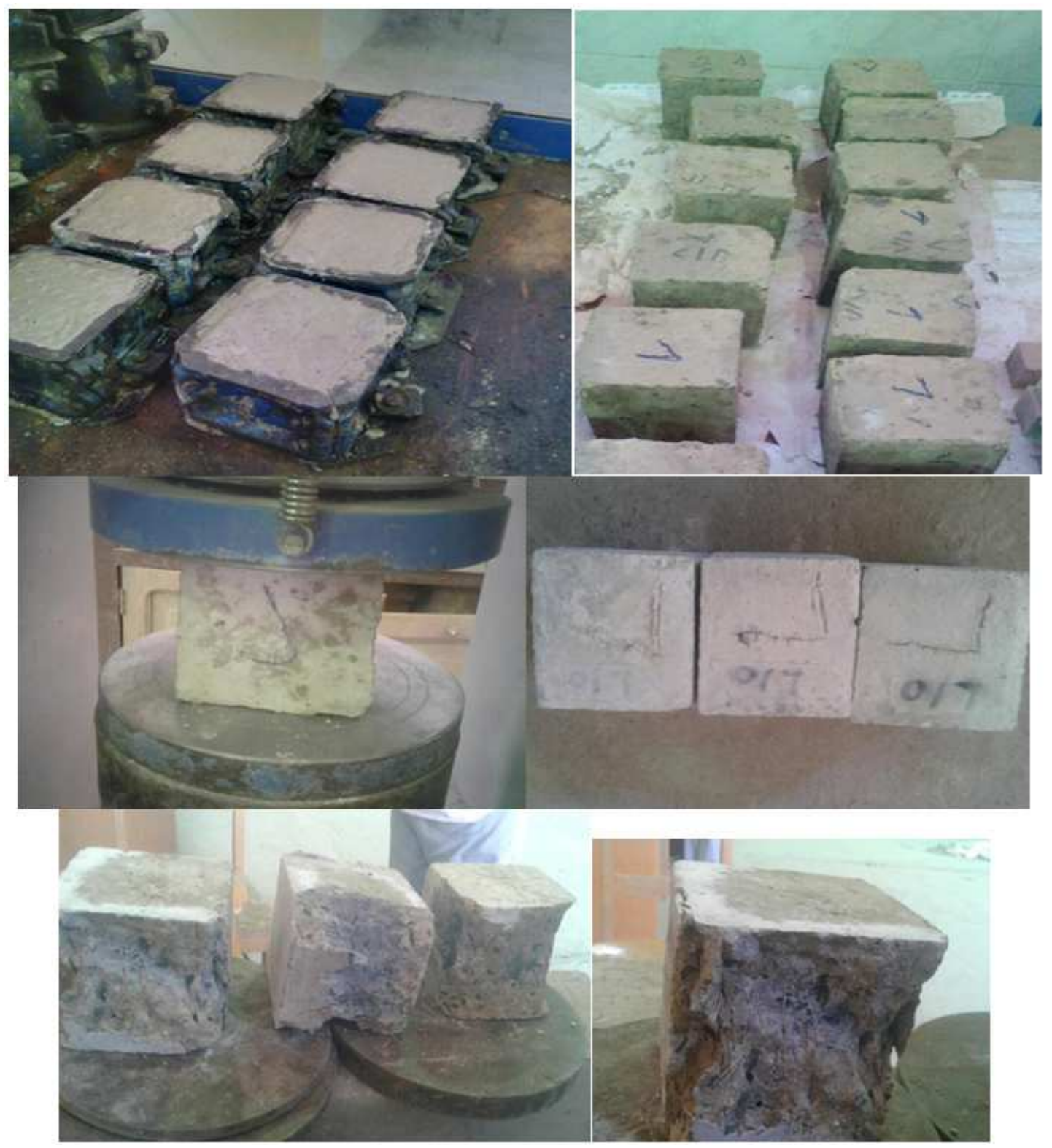

Figure 3. The geopolymer concrete cubes during cast and test.

\subsubsection{Instrumental Analyses}

Axios (PW4400) WD-XRF Sequential Spectrometer (Panalytical, Netherland) were used for chemical analysis of the starting raw materials. XRD analysis was recorded on a Philips PW 1050/70 Diffractometer using a $\mathrm{Cu}-\mathrm{K} \alpha$ source with a post sample $\mathrm{K} \alpha$ filter. XRD patterns were collected from $0 \mathrm{o}$ to $50 \mathrm{o} 2 \Theta$ (step size $0.02 \mathrm{o} 2 \Theta$ and speed $0.4 \mathrm{o} / \mathrm{min}$ ).
Bonding characteristics of the specimens were analyzed using a Jasco-6100 Fourier transformed infrared spectrometer FTIR. Test sample was ground and uniformly mixed with $\mathrm{KBr}$ at a weight ratio $\mathrm{KBr}$ : specimen $=200: 1$. The mixture, $0.2 \mathrm{~g}$ was pressed to a disk of $13 \mathrm{~mm}$ in diameter for analysis at $8 \mathrm{t} / \mathrm{cm}^{2}$. The wave number was ranging from 400 to $4000 \mathrm{~cm}^{-1}[11,12]$. 


\section{Results and Discussion}

\subsection{Optimization of Slag Meta-Koline Mix as Binder in Geopolymer Concrete}

\subsubsection{Effect of Alkali Activator on Compressive Strength of Binder}

Alkaline activator is the second part in geopolymer.
Variations in types of activators and $\mathrm{SiO}_{2}$ to $\mathrm{Na}_{2} \mathrm{O}$ ratio were proved to have great effect on the properties of geopolymer cement. The effect of sodium hydroxide, sodium silicate ratio on slag geopolymer is shown in Figure (4) at different interval times. The best compressive strength is obtained at $30 \%$ sodium silicate in both time intervals and recorded 52 $\mathrm{N} / \mathrm{mm}^{2}$ at 28 days.

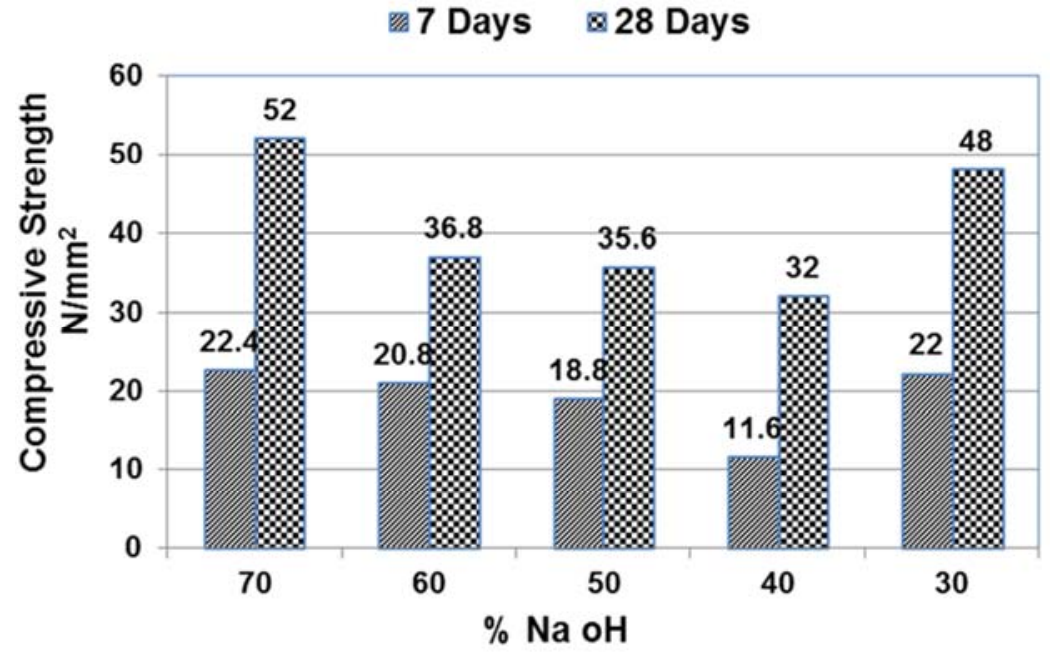

Figure 4. Effect of $\mathrm{SiO} 2$ to $\mathrm{Na2O}$ ratio in compressive strength of slag geopolymer at different interval times.

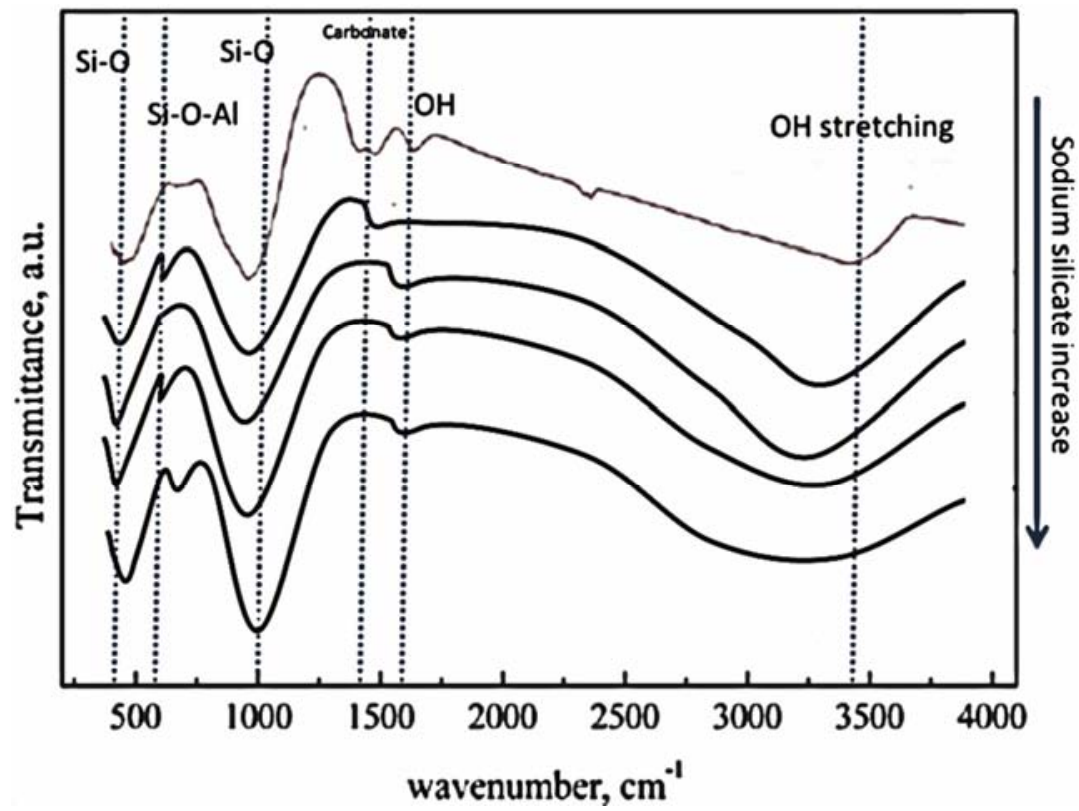

Figure 5. FTIR analysis and identification of cement paste at different concentration at 28 days.

FTIR of sample in figure (4) is determined and identified in figure (5). Variations in FTIR sample have shown a change in wave number and a transmission of the sample. According to that, the increase in sodium silicate gets an increase in wave number as it increases the stability of $\mathrm{Si}-\mathrm{O}$ bonds and decreases the density of $\mathrm{OH}$ group uninformed which appears as $1570 \mathrm{~cm}^{-1}$. Si-O-Al density increases with the increase in sodium silicate, but the wave number decreases to indicate less stable form.

\subsubsection{Effect of Replacement of Slag by Metakoline}

According to the determination of FTIR in the slag geopolymer, the stability of Si-O-Al decreases in correlation with increases in dense structure of geopolymer. This means formation of more geopolymer with low stability. Metakoline have alumina structure with high values. The variation in slag metakoline ratio is studied at certain values of activator ratio according to the above ratio. The effect of slag, the metakoline ratio of geopolymer compressive 
strength is shown in Figure (6) at different interval times.

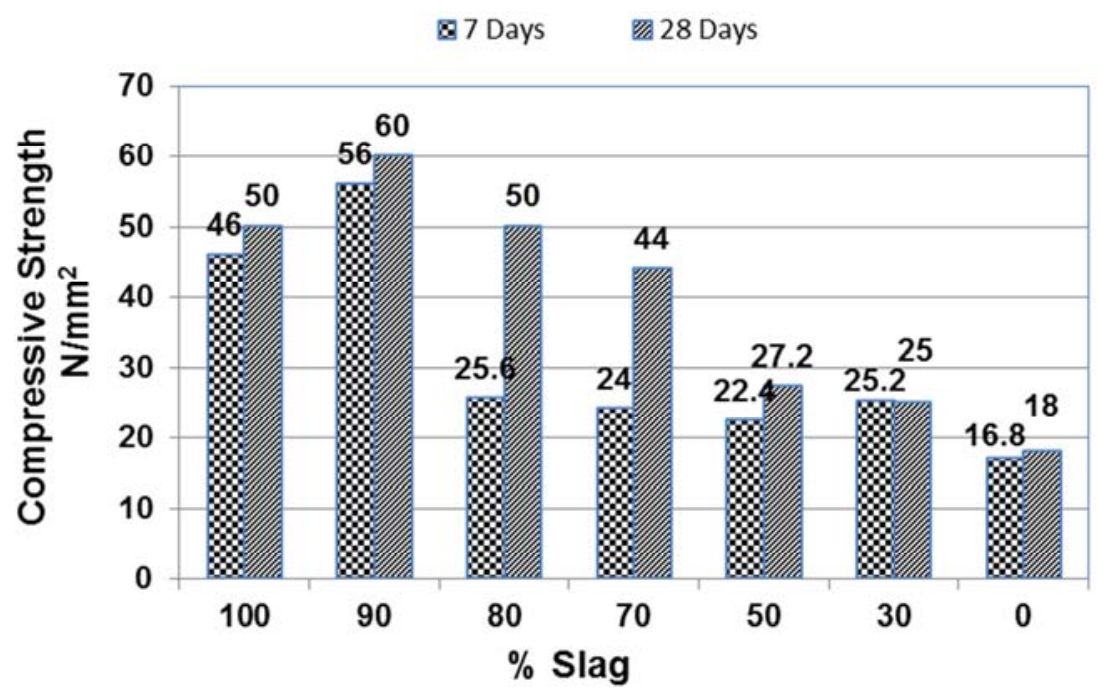

Figure 6. The effect of slag, meta koline ratio of geopolymer compressive strength at different interval times.

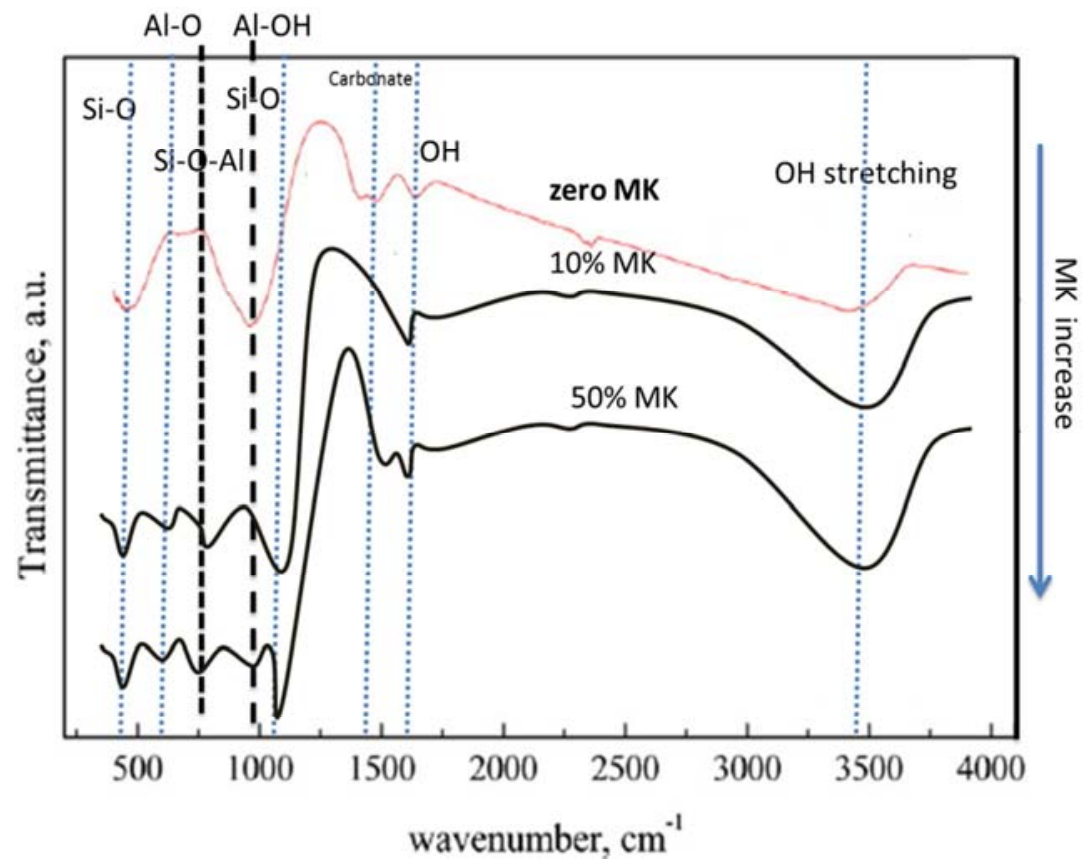

Figure 7. FTIR analysis and identification of cement paste at different concentration at 28 days.

Figure (6) points to increases in compressive strength of geopolymer up to $10 \%$ metakoline but this behavior is reflected up to $100 \% \mathrm{Mk}$. Compressive strength increases may deal with the formation of more stable geopolymer and decreases in the compressive strength may be due to the less formation of geopolymer structure due to the increases in the Alumina silica ratio. The best compressive strength is obtained at $10 \% \mathrm{Mk}$ in both time intervals and recorded 60 $\mathrm{N} / \mathrm{mm}^{2}$ at 28 days.

Figure (7) demonstrates a variation in function group; this variation returns to the high value of aluminum content in Mk. The variation presents two main changes due to the addition of MK. The first change is related to the formation of more concentration of Al-O-Si at $600 \mathrm{~cm}^{-1}$. The second change, however, is related to the shift of band to high wave number which means more stable formation. As well, the increasing percentage in $\mathrm{MK}$ causes formation of $\mathrm{AL}-\mathrm{OH}$ which consequently consumes alkaline activator and aluminum content and form the internal strength which causes a high reduction in compressive strength. These results are matched with the compressive strength.

\subsection{Optimization of Concrete}

\subsubsection{The Effect of Binder Geopolymer Ratio in Geopolymer Concrete}

The binder of gaopolymer content directly effects on the characterization of concrete, table (4) present the mix design of geopolymer concrete at different content of geoplymer cement. 
Table 4. Mix design of geopolymer at different gopolymer cement using fresh water.

\begin{tabular}{|c|c|c|c|c|c|c|c|}
\hline $\operatorname{mix}$ & $\begin{array}{l}\text { Geo cement } \\
\mathrm{Kg} / \mathrm{m}^{3}\end{array}$ & $\mathrm{Na}_{2} \mathrm{SiO}_{3}$ Lit. & NaOH Lit. & C. $\mathrm{A} \mathrm{Kg} / \mathrm{m}^{3}$ & F. A Kg/m $\mathrm{m}^{3}$ & $\begin{array}{l}\begin{array}{l}\text { Strength for } 7 \\
\text { days N/mm }\end{array} \\
\end{array}$ & $\begin{array}{l}\text { Strength for } 28 \\
\text { days } \mathrm{N} / \mathrm{mm}^{2}\end{array}$ \\
\hline 1 & 350 & 132.5 & 53 & 1322.4 & 661.2 & 20.5 & 28.4 \\
\hline 2 & 400 & 151.43 & 60.57 & 1283.7 & 641.8 & 23.7 & 34.3 \\
\hline 3 & 450 & 170.36 & 68.14 & 1216.9 & 608.4 & 27.2 & 38.9 \\
\hline 4 & 500 & 189.29 & 75.7 & 1150.1 & 575.1 & 29 & 41.3 \\
\hline 5 & 550 & 208.2 & 83.3 & 1083.4 & 541.7 & 34.1 & 49.2 \\
\hline 6 & 600 & 227.14 & 90.86 & 1016.5 & 508.28 & 38.9 & 52.8 \\
\hline
\end{tabular}

The effect of binder content at different values of compressive strength of geopolymer concrete at different interval times are shown in Figure (8).

\section{Mix with Fresh Water}

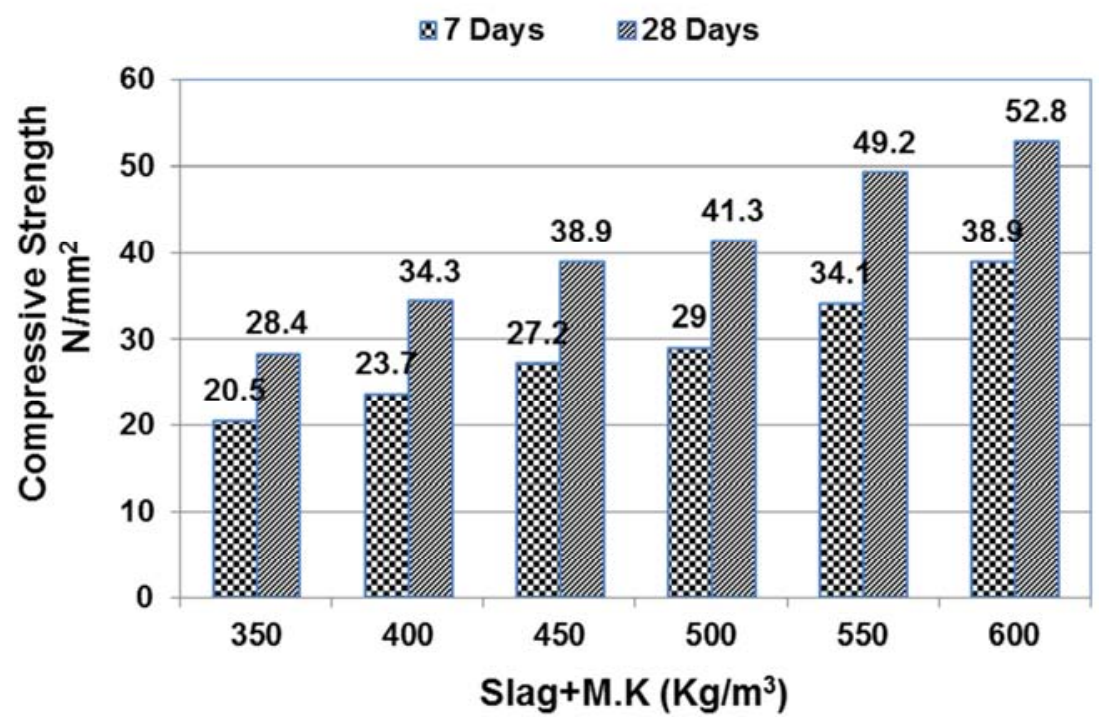

Figure 8. The variation in geopolymer cement content with compressive strength of geopolymer concrete at different interval times.

Figure (8) sheds light upon increases in compressive strength attached with increases in geopolymer cement content in both interval times. The variation in the compressive strength is considered an advantage of geopolymer concrete. The compressive strength has changed from 20.5 to $38.9 \mathrm{~N} / \mathrm{mm}^{2}$ with a change in cement content from 350 to 600 respectively at 7 days. At 28 days compressive strength has been noted to range from 28.4 to $52.8 \mathrm{~N} / \mathrm{mm}^{2}$.

\subsubsection{The Effect of Sea Water as an Alternative of Fresh Water}

Different countries suffer the lack water. This is a trial to use seawater as alternative to fresh water in concrete geopolymer. Table (5) presents the mix design of geopolymer concrete at different contents of geoplymer cement by using seawater in concrete.

Table 5. Mix design of geopolymer at different gopolymer cement using sea water.

\begin{tabular}{|c|c|c|c|c|c|c|c|}
\hline $\operatorname{mix}$ & $\begin{array}{l}\text { Geo cement } \\
\mathrm{Kg} / \mathrm{m}^{3}\end{array}$ & $\mathrm{Na}_{2} \mathrm{SiO}_{3}$ Lit & NaOH Lit. & C. A Kg/m $\mathrm{m}^{3}$ & F. A Kg/m $\mathbf{m}^{3}$ & $\begin{array}{l}\text { Strength for } 7 \\
\text { days } \mathrm{N} / \mathrm{mm}^{2}\end{array}$ & $\begin{array}{l}\text { Strength for } 28 \\
\text { days } \mathrm{N} / \mathrm{mm}^{2}\end{array}$ \\
\hline 1 & 350 & 132.5 & 53 & 1322.4 & 661.2 & 23.5 & 32.7 \\
\hline 2 & 400 & 151.43 & 60.57 & 1283.7 & 641.8 & 27 & 37.5 \\
\hline 3 & 450 & 170.36 & 68.14 & 1216.9 & 608.4 & 30.3 & 42.1 \\
\hline 4 & 500 & 189.29 & 75.7 & 1150.1 & 575.1 & 33.7 & 46.8 \\
\hline 5 & 550 & 208.2 & 83.3 & 1083.4 & 541.7 & 37.2 & 52.7 \\
\hline 6 & 600 & 227.14 & 90.86 & 1016.5 & 508.28 & 40.4 & 56.1 \\
\hline
\end{tabular}

The effect of binder content at different values and compressive strength of geopolymer concrete at different interval times in seawater are shown in figure (8).

Figure (9) sets forth increases in compressive strength in correlation with increases in geopolymer cement content in both interval times. The variation in compressive strength is considered an advantage of geopolymer concrete. Concerning the variation in compressive strength in seawater as compared to that in the fresh water, it has been noticed that compressive strength has increased in sea water more than in 
fresh water. The compressive strength in sea water has changed from 23.5 to $40.4 \mathrm{~N} / \mathrm{mm}^{2}$ with a change in cement content from 350 to 600 respectively at 7 days. At 28 days, compressive strength noted from 32.7 to $56.1 \mathrm{~N} / \mathrm{mm}^{2}$. This may be related to the stability of geoplymer structure as compared with this formed in fresh water.

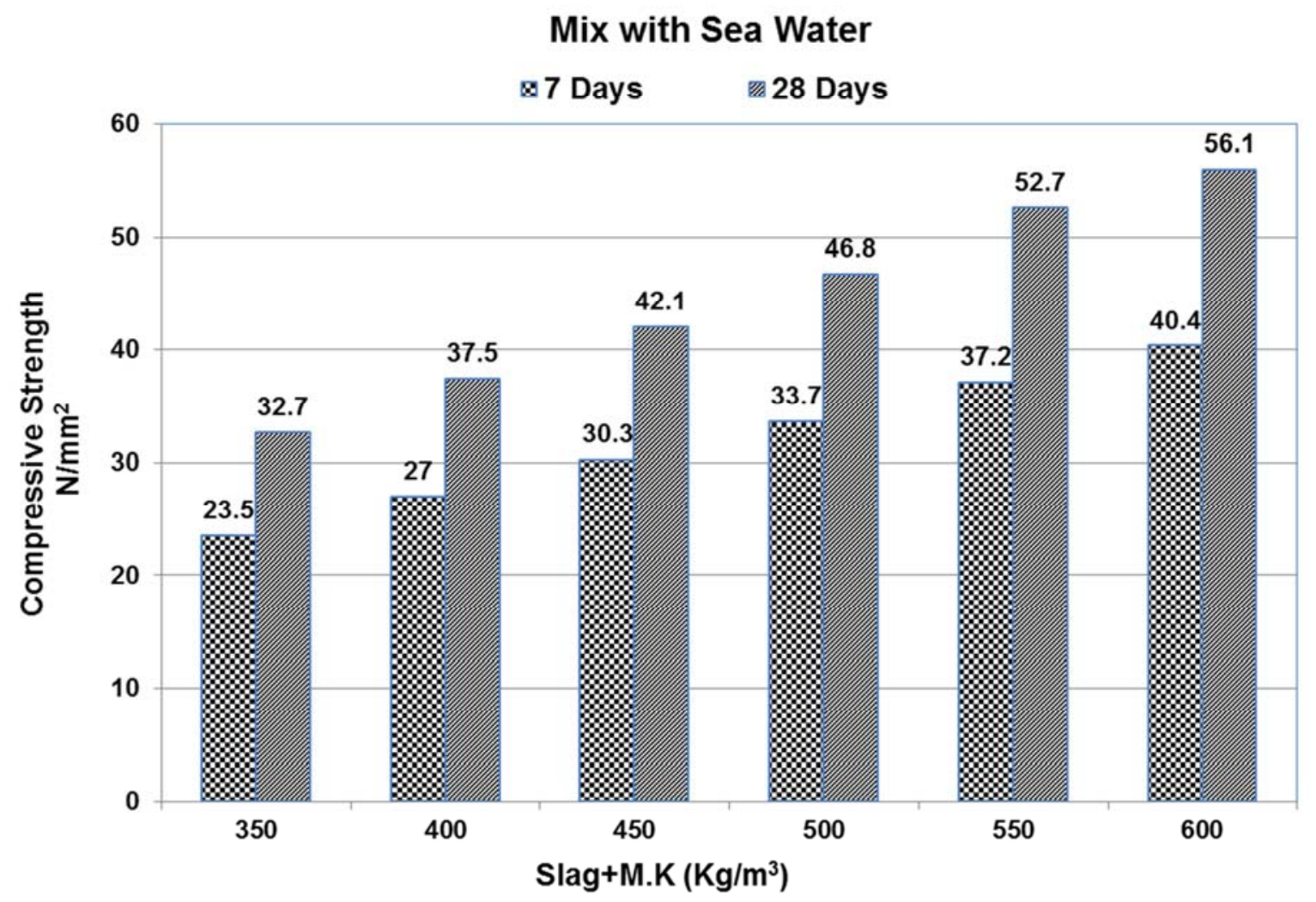

Figure 9. The variation in geopolymer cement content with compressive strength of geopolymer concrete at different interval times in seawater as mixing water.

\section{Conclusion}

In trying to find the ability to formation of geopolymer cement and the ability to use this cement in the formation of geopolymer concrete in the field. During this paper are studied in air without any types of curing. Also the improvement of cement by meta koline as a source of aluminium and silica are studied. Water in geopolymer cement not included in the reaction so that during this paper the sea water id used as an alternative to fresh water. The following conclusions can be drawn:

(1) Geopolymer cement is a good alternative to traditional types of cement.

(2) Slag geopolymer can be improved with the replacement by Metakoline up to $10 \%$ of slag content.

(3) Geopolymer structure gets more stable form in presence of MK.

(4) Compressive strength of geopolymer concrete increases with the increasing of geopolymer cement content.

(5) Sea water can be used as a mixing water of geopolymer concrete.

(6) Seawater, as mixing water, improves concrete geopolymer if compared with geopolymer treated with fresh water.

\section{References}

[1] Mehta P. K. "Greening of the Concrete Industry for Sustainable Development", Concrete International (2002), 24 (7): pp. 23-28.

[2] Hardjito D, Wallah S. E, Sumajouw D. M. J. and Rangan B. $\mathrm{V}$, "Factors Influencing the Compressive Strength of Fly ashbased Geopolymer Concrete", Civil Engineering Dimension, Vol. 6, No. 2, pp. 88-93, September 2004.

[3] Salloum T, "Effect of Fly ash Replacement on Alkali and Sulphate Resistance of Mortars", published master's thesis, Department of Building, Civil and Environmental Engineering, Concordia University Montreal, Quebec, Canada, July 2007.

[4] Davidovits J, "Geopolymer chemistry \& sustainable development. The Poly silicate terminology: a very useful and simple model for the promotion and understanding of green-chemistry", Proceedings of the World Congress Geopolymer, Saint Quentin, France, 28 June - 1 July, 2005: pp. 9-15.

[5] Malhotra V. M, "Introduction: Sustainable Development \& Concrete Technology”, Concrete International (2002), 24 (7): pp. 22. 
[6] K. Parthiban, K. saravana raja mohan, S. Sobana, A. Anchal Bhaskar, "Effect of Replacement of Slag on the Mechanical Properties Of Fly ash based Geopolymer Concrete", International Journal of Engineering and Technology (IJET), 2013, ISSN: 0975-4024, Page 25552559.

[7] Ganapati Naidu, A. S. S. N. Prasad, S. Adiseshu, P. V. V. Satayanara "A study on strength properties of Geopolymer Concrete with the addition of GGBS", International Journal of Engineering Research and Development (IJERD), 2012 ISSN: 2278-800, Page 19-28.

[8] Partha Sarathi Deb, Pradip Nath, Prabir Kumar Sarker, "The Effects of GGBFS blending with Flyash and activator content on the workability and strength properties of Geopolymer concrete cured at ambient temperature ", Material \& design, 62 (2014), page 32-39.
[9] Pradip Nath, Prabirkumar Sarker "Effect of GGBFS on Setting, Workability and early Strength properties of flyash Geopolymer Concrete", construction and building materials, 2014, 66, page 163-171.

[10] Vásquez, A, Cárdenas, V, Robayo, R. A, \& de Gutiérrez, R. M. "Geopolymer based on concrete demolition waste" Advanced Powder Technology, 2016, 27 (4), 1173-1179.

[11] Panias, Dimitrios, Ioanna P. Giannopoulou, and Theodora Perraki. "Effect of synthesis parameters on the mechanical properties of fly ash-based geopolymers." Colloids and Surfaces A: Physicochemical and Engineering Aspects 301.1 (2007): 246-254.

[12] El-Sayed, H. A, Abo El-Enein, S. A, Khater, H. M. and Hasanein, S. A. "Resistance of alkali activated water cooled slag geopolymer to sulfate attack", Ceramics-Silikáty, 2011, 55, 153-160. 